International Journal of

Environmental Research and

Public Health

ISSN 1660-4601

www.mdpi.com/journal/ijerph

Review

\title{
Seasonality of Suicidal Behavior
}

\section{Jong-Min Woo ${ }^{1,2}$, Olaoluwa Okusaga ${ }^{3,4}$ and Teodor T. Postolache ${ }^{3,4, *}$}

1 Department of Psychiatry, Seoul Paik Hospital, Inje University School of Medicine, Mareunnae-ro 9, Jung-gu, Seoul, 100032, Korea; E-Mail: jongmin.woo@gmail.com

2 Stress Research Institute, Inje University, 607 Obang-dong, Gimhae, Gyungnam, 621749, Korea

3 Psychiatry Residency Training Program, St. Elizabeth's Hospital, 1100 Alabama Avenue, Washington, DC 20032, USA; E-Mail: olaokusaga1@yahoo.com

4 Mood and Anxiety Program (MAP), Department of Psychiatry, School of Medicine, University of Maryland, Baltimore, MD 21201, USA

* Author to whom correspondence should be addressed; E-Mail: tpostolache@psych.umaryland.edu.

Received: 16 December 2011; in revised form: 11 January 2012 / Accepted: 26 January 2012 /

Published: 14 February 2012

\begin{abstract}
A seasonal suicide peak in spring is highly replicated, but its specific cause is unknown. We reviewed the literature on suicide risk factors which can be associated with seasonal variation of suicide rates, assessing published articles from 1979 to 2011. Such risk factors include environmental determinants, including physical, chemical, and biological factors. We also summarized the influence of potential demographic and clinical characteristics such as age, gender, month of birth, socioeconomic status, methods of prior suicide attempt, and comorbid psychiatric and medical diseases. Comprehensive evaluation of risk factors which could be linked to the seasonal variation in suicide is important, not only to identify the major driving force for the seasonality of suicide, but also could lead to better suicide prevention in general.
\end{abstract}

Keywords: seasonality; suicide; prevention

\section{Introduction}

Several epidemiological studies have described a seasonal variation of suicide rates, with a highly replicated suicide peak in springtime [1,2]. However, recent studies have shown that the amplitude of 
the spring peak is on the decline, while new small peaks are occurring at other times of the year, especially in industrialized Western countries [3,4]. In spite of it being a well replicated phenomenon, the empirical finding of seasonal peaks in suicide is poorly understood.

To date many risk factors for suicide have been reported and they can be categorized by demographic, social and clinical characteristics. Such risk factors include age, gender, rural/urban area of residence [5], race [6], month of birth [7], socioeconomic factors [8], marital status [9], inter-personal relationships or life events $[10,11]$, comorbid medical conditions, current or history of psychiatric illness [12], allergy [13], and most importantly, previous suicide attempts and violent methods of prior suicide attempt [2,14]. Physical environmental factors, e.g., sunshine, temperature [15], chemical (e.g., air pollutants) [16] and biological factors such as viruses [17], parasites such as Toxoplasma gondii, and aeroallergens $[18,19]$ have also been associated with suicide risk.

Among the numerous risk factors for suicide, it is important to define those that are fluctuating, modifiable, and potentially treatable. Since the seasonal fluctuation in suicide has become a recognized and significant phenomenon, it is desirable to identify variables that consistently demonstrate an association with the seasonal variation of suicidal behaviors as well as completed suicide. For example, environmental factors such as the amount of sunshine and distribution of aeroallergens vary with the seasons. Moreover, clinical variables such as allergic illness, viral infections and mood disorders also manifest seasonal variations and such variations could potentially be associated with the seasonal variation of suicide rate.

A better understanding of the underlying mechanisms responsible for the seasonal variations in suicide could lead to improved and novel suicide prevention strategies. Therefore we comprehensively evaluated published papers, focusing on the potential association between suicide risk factors and seasonal fluctuation of suicide completion in various demographic groups and geographic locations. We also discuss the presence of seasonality of suicide, the strength and the clinical implication of the association for each risk factor.

\section{Methods}

This is a comprehensive narrative review of journal papers on suicide seasonality published from 1979 to 2011. We carried out a comprehensive search of PubMed/MEDLINE (1979-2011) using the keywords: "suicide" and "seasonality", cross-referenced with the terms "age", "gender", "methods of suicide", "socioeconomic status", "sunshine", "temperature", "geographic region", "comorbid disease", "allergy", "mental illness", "infection", and "cytokine". After we had identified potential publications of interest we read through the titles and abstracts and those selected were subsequently reviewed and categorized by suicide risk factors of interest. We only included articles in English. Among those, reports dealing with seasonality or monthly fluctuation were taken to review the relationship between seasonality and suicide.

\section{Potential Environmental Mediators}

Environmental factors have been considered as possible mediators of the seasonal variation in human behaviors and therefore may also influence suicidal behaviors. Here we review physical (i.e., bioclimatic factors such as sunshine, temperature and rainfall), chemical (i.e., pollutants), and 
biological (i.e., viruses, bacteria, protozoa and allergens) factors as potential triggers of suicidal behaviors in spring or fall.

\subsection{Bioclimatic Factors}

Bioclimatic factors have been suggested to be potential mediators of the seasonal variation in suicide, though this concept is controversial. Some researchers have documented a positive association between sunshine/temperature/humidity and suicide [20-26], while others dispute this relationship [27-30]. In addition, a few studies concluded that a positive association between climatic factors and seasonal variation of suicide was present only for suicide by violent methods [14,31].

Petriduo et al. [32] suggested that sunlight may act as a trigger of suicide. In addition, suicide rates are greater in rural areas than in urban areas $[2,4,33,34]$ and higher among outdoor workers compared to indoor workers [35]. Some empirical findings support the notion that the intensity of sunlight may play a role in the triggering of suicide and therefore provide a potential link to the seasonal variation in suicide. Hiltunen et al. reported the association between increased suicide mortality and the period with the longest day length (which was between May and July) i.e., late spring/early summer [36]. Another study in Greenland reported a similar pattern. However, both studies suggested the role of latitude and other signals besides the variation in daylight, as the suicide peak of the northern area of Finland (Oulu) was delayed when compared to the southern area (Helsinki) and the strength of the suicide peak was more pronounced at higher latitudes [36,37]. A recent analysis of data from Finland suggested a correlation between solar radiation and suicide mortality [38] but other studies have also suggested that seasonal suicide peak in spring occurs significantly later than the interval of change in day length [39-41]. Furthermore, Papadopoulos et al. [42] hypothesized that a time lag exists for the effect of solar radiance on suicidality. In summary, seasonal changes in sunlight seem unlikely to fully account for the seasonal variation in suicide.

With regard to temperature, a study performed by Volpe et al. [25] found that suicide rates in Brazil not only showed a higher peak in December and January than the rest of the year, but were also significantly correlated with increasing temperature. In addition, Kim et al. [15] reported a $1.4 \%$ increase in suicide when temperature goes up by 1 degree Celsius. Temperature could either be a marker of seasonal change, or the mediator of it. In addition, specific meteorological conditions such as temperature and thunderstorm for the preceding day could contribute to increased risk of suicide in individuals [26].

Precipitation (rainfall and snowfall) is another climatic factor that shows seasonal variation and has thus been postulated to possibly be predictively associated with seasonality of suicide. When AjdacicGross et al. [28] modeled monthly data on suicide and precipitation in Switzerland precipitation did not show any noteworthy effects on suicide frequencies. Lin et al. also examined the association between monthly suicide rates and climatic influences including atmospheric pressure, temperature, sunshine, humidity, and rainfall in Taiwan; however, they only found evidence of an association of temperature with seasonality, but reported no significant association between rainfall and seasonal peaks of suicide in spring/early summer [43]. 


\subsection{Geographic Location}

Chew and McCleary [4] comprehensively compared the seasonal variation of suicide across 28 nations and found well replicated seasonal spring peaks in suicide rates from the various nations regardless of the location of the countries. They also observed wide cross-sectional variation in degree of suicide seasonality. For instance, when comparing Canada to Portugal they demonstrated a narrow range of seasonal fluctuation in Canada (ratio of average spring to average winter $=1.08$ ) versus wide fluctuation of seasonal suicide rates in Portugal (ratio of average spring to average winter $=1.70$ ) implicating a more prominent seasonal spring peak in Portugal.

Consistent with the pattern in the northern hemisphere, Flisher et al. [44] reported a mirror image spring or summer peak of suicide and a trough in fall in South Africa, especially for less urbanized subpopulations. Similarly, studies in Australia [24] are concordant with studies conducted in the Northern Hemisphere in Europe [1,10,11,32,45-48] and Asia [18,49,50], identifying a seasonal spring suicide peak.

\subsection{Allergens}

Allergy has been previously linked to suicide [13]. The seasonality of suicide has been shown to co-occur with the seasonal peaks in ambient pollen concentration during spring (i.e., tree pollen), summer (i.e., grass pollen), and fall (i.e., ragweed) [19]. Pollens are aeroallergens and are capable of inducing an allergic inflammatory reaction when they reach the intranasal mucosa of susceptible individuals. The inflammatory reaction induced by aeroallergens involves the production of Th2 cytokines which, in animal models, have been associated with increased anxiety-like behavior, reduced social interaction [51] and aggressive behavior [52] all of which can be considered as endophenotypes for suicidal behavior [53]. Furthermore, the seasonal peak in aeroallergens resulting in the concomitant worsening of allergy symptoms could (via inflammatory mediators of worsening allergy symptoms) potentially worsens depressive symptoms, anxiety and impulsivity in mood disorder patients, resulting in exacerbated risk of suicidal behavior. Consistent with this notion, Manalai et al. [54] recently reported that in bipolar patients pollen-specific IgE positivity and worsening of allergy symptoms are associated with worsening of depression scores during exposure to aeroallergens. In addition, changes in allergy and anxiety (anxiety representing a potentially independent suicide risk factor) in patients with mood disorders exposed to seasonal peaks of aeroallergens were observed to be correlated [54]. In essence, the current available evidence makes seasonal fluctuation of aeroallergens a possible factor involved in the underlying mechanisms responsible for seasonality of suicide. This is particularly important from a neuroimmune perspective, considering a previous study showed an increased gene expression for cytokines involved in allergic reactions in the orbitofrontal cortex (a region previously implicated histopathologically with suicide) in victims of suicide [53].

\subsection{Viruses}

The human immunodeficiency virus (HIV) has been associated with suicide [55] but no seasonal pattern has been reported in relation to HIV-related suicide rates neither has HIV been known to 
manifest a seasonal pattern of infectivity. The influenza virus, on the other hand, has a seasonal pattern of infectivity. However the only report of an association of influenza with suicidal behavior [17] did not include an evaluation of seasonality effect on suicide. More studies on the association of seasonal viruses and suicide are needed.

\subsection{Pollutants}

Air pollutants have been correlated with rates of visits to the emergency room as well as inpatient admission rates of patients with mental illness [56]. Recently Kim et al. [16] found that the rate of completed suicide in the Republic of Korea was elevated when there was an increase in the ambient particulate matter two days prior to the day of suicide. The two aforementioned studies did not take into consideration the impact of the season on elevation of suicide risk. Szyszkowicz [57], however, carried out an analysis of data on air pollution effect on emergency room (ER) visit for worsening depression by season and found that the highest percentage of depression-related ER visits were during periods of increased concentration of ambient particulate matter during the cold season and the finding was limited to only females. However, the findings by Szyszkowicz should be interpreted with caution (in terms of elucidation of the seasonality effects of air pollutants on depression), since the analysis did not include an assessment of an interaction between season and pollutant but rather an analysis by season was carried out. It therefore appears that the literature on the potential contribution of pollutants to the seasonality of suicide is sparse and no generalization can be made at this time.

\section{Clinical Determinants: Effect of Morbidity}

It has been well described that psychiatric disorders are associated with suicide and at the time of suicide completion, more than $90 \%$ of suicide victims suffer from a psychiatric disorder [58]. Reports from Finland showed an association between time patterns of attempted suicides and psychiatric disorders (e.g., mood disorders, substance use disorders and schizophrenia-related disorders [59,60].

However, studies on the relationship between seasonal variation in the occurrence or exacerbation of mental disorders and suicide seasonal peaks are limited [45,61,62]. A study [61] conducted in Sweden showed a seasonal spring/early summer peaks among patients diagnosed with neurotic, stressrelated, or somatoform disorder; however, only patients with symptoms severe enough to require hospitalization were studied. Consistent with this study, Brådvik et al. [62] demonstrated a seasonal spring peak of suicide in a study of male patients with alcohol addiction. Rocchi et al. [45] also reported on the seasonality of suicide completion among patients with psychiatric illnesses. Recently, Postolache et al. [63] reported an increased amplitude of the suicide peak in spring among victims of suicide with a history of mood disorders (see Figure 1). Another study carried out by Kim et al. [64] demonstrated seasonal spring/summer peak of suicide completion in depression and fall/winter peak in schizophrenia.

In addition, significant seasonal peaks were reported in allergy-related asthma, rhinitis, and atopic dermatitis. As allergy-related diseases are associated with suicide completion, seasonal changes in

allergens may lead to seasonal increase in incidence and exacerbation of allergic disorders which in turn could potentially be associated with peak in suicide rates, mediated through molecular and cellular 
components of allergic inflammation affecting the brain [13]. Indeed, Timonen et al. [65] revealed an association between prior hospitalization for atopic disorders and seasonal variation of suicide.

Figure 1. Monthly rates of suicide based upon all cases of suicide from 1970 to 2001 in the Danish Cause of Death Registry. History of mood disorder was obtained from the Danish Psychiatric Central Register. The authors estimated the monthly rate ratio of suicide relative to December. Conditional logistic regression analyses with adjustment for place of residence, marital status, income, and method of suicide were used to compare seasonality of suicide in victims with versus without hospitalization for mood disorders. A statistically significant spring peak in suicide was observed in both groups. A history of mood disorders increased the risk of suicide in spring (for males: $\mathrm{RR}=1.18,95 \% \mathrm{CI} 1.07-1.31$; for females: $\mathrm{RR}=1.20,95 \% \mathrm{CI} 1.10-1.32$ ). Reproduced from [19] with permission.

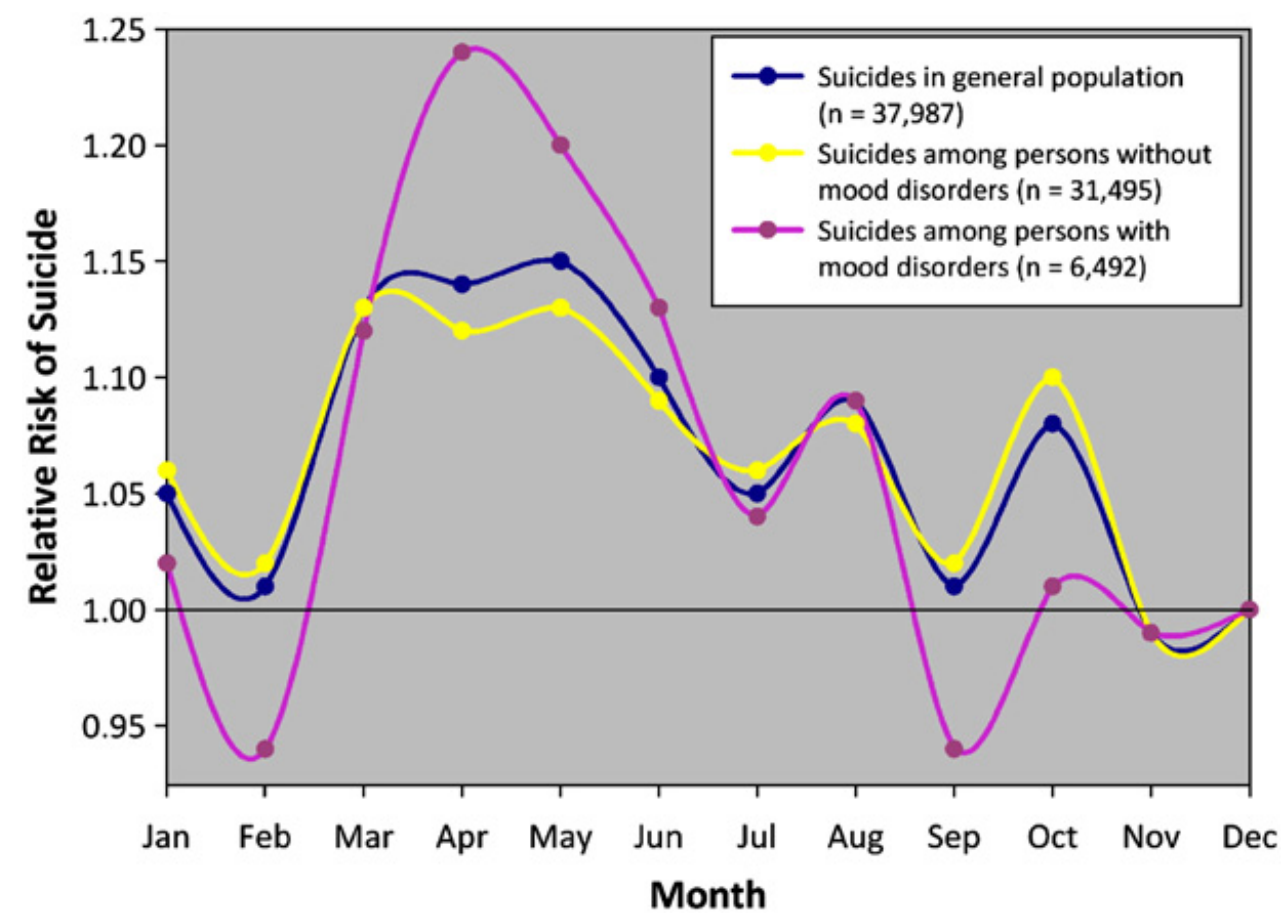

\section{Demographic Variables}

\subsection{Age}

Several studies have found associations between age and seasonal variation in suicide. Maes et al. [2] reported that the suicide rate among younger people was increased in spring (i.e., March and April), whereas the rate within older adults was raised in late summer (i.e., August). However, Lahti et al. [66] observed a suicide peak in fall among adolescents, particularly for those dying by shooting. Furthermore, McCleary et al. [67] documented that a suicide peak was observed in younger aged individuals in winter and fall, while suicide among the very old was elevated towards the summer period. The inconsistency between studies may reflect methodological or environmental differences between studies and at the moment, no conclusion can be drawn. 


\subsection{Gender}

Although seasonality of suicide completion is seen both in men and women, the seasonal patterns differ between genders. For example, only a single spring peak is found in men, while two peaks in spring and fall have been reported in women [4,33,34,40,68]. In England, middle aged women who had school-aged children were more likely to commit suicide in fall, which was the beginning of the school year [4,69]. Though speculative, it may be that a sudden reduction in the duration of direct contact with a dependent represents a type of suicide risk in these women. Gender effect on seasonality of suicide was also noted in Hungary where a steadily increasing prescription rate for antidepressants was associated with a decrease in national suicide rate but significantly decreased seasonality of suicide only in males [70]. The suicide peak in spring has been considered to be a consequence of seasonal occurrence of depression-related suicides and the decreased seasonality of suicide in this Hungarian study was suggested to be a marker of lowering depression-related suicides (especially among men) as a result of increased antidepressant utilization in the population [70].

Seasonality of suicide attempts is also shown to be associated with gender [71]. Studies performed in Scotland and in Oxford revealed a seasonal variation of female suicide attempts with increased rates during summer and decreased rates in winter, but no significant seasonal variation of male suicide attempts was found [72,73]. In addition, the results of the WHO/EURO Multicenter study on Parasuicides indicated that the seasonal pattern of suicide attempts in women showed a peak in spring and nadir in winter, but no significant variation of suicide attempts was observed within the male subpopulation [74]. However, there have been negative reports as well. Mergl et al. analyzed suicide attempts in Nuremberg and Wuerzburg from 2000 to 2004 and they failed to confirm the significant gender difference in seasonality of suicide attempts [71]. Kreitman et al. also reported no considerable gender difference in seasonality of suicide attempts in the U.S. [75].

\subsection{Month of Birth}

While several studies have reported season of birth effect on suicide or suicidal behavior [7,76-78], there is lack of evidence to indicate an association between month of birth and seasonality of suicide completion. Dome et al. [76] found a significantly increased risk of suicide completion among those individuals who were born in spring and summer, however, this study did not show any relationship between season of birth and seasonal variation of suicide. Another study which evaluated the effect of birth month on suicidal behavior in Western Australia reported a notable spring peak of deliberate selfharm and a significantly increased birth in spring within the deliberate self-harm group [7]. However, no season-of-birth effect was observed in relation to completed suicide in the study.

\subsection{Socioeconomic Factors}

Socioeconomic status can affect suicide rates. Social discrepancy, disputes, socio-economic gradient (urban-rural income gradient, etc.), divorce and resulting single parent family environment can be related with seasonality of suicide. The majority of research findings indicated that the seasonal spring peaks are greater in rural areas compared to urban areas [2,4,79]. In particular, Micciolo et al. [79] evaluated the seasonality of suicide in Italy from 1969 to 1984 and found the suicide peaks in spring to be more 
notable in rural areas than in urban areas, although the suicide rates was higher in urban regions. A review by Christodoulou et al. [80] suggested that this phenomenon might plausibly be related to intensity of seasonal activities such as agricultural work in the rural areas. In fact, Chew and McCleary [4] reported that the spring peak of suicide is relatively larger in agricultural countries compared to industrial countries. They also found that the larger amount of agricultural work is significantly correlated with the greater spring peak of suicide. Ajdacic-Gross et al. [81] further posited that as the traditional rural society is disappearing with industrialization, the seasonal variation of suicides might be attenuated.

In addition, seasonality of suicide has been shown to be related to occupational differences. The agricultural and construction sectors usually have intense activity from spring to fall. Näyhä [40] found that suicide committed by people who served in technical, administrative, and service work (i.e., modern occupations) usually peaked in late fall, while people who engaged in traditional occupations (e.g., agriculture, transport, or manufacturing work) showed seasonal peaks of suicide in spring/ summer. Koskinen et al. [35] also examined seasonality of suicide in different occupations including farmers, forest workers, construction, and indoor workers. They documented that spring peak and winter trough of suicide pattern was observed in groups of farmers and forest workers. On the contrary, a significant summer nadir was shown within indoor workers. Moreover, in their sub-group analyses by suicide methods, $90.5 \%$ of farmers used violent methods, followed by forest workers $(79.1 \%)$, construction (73.2\%), and indoor workers (69.2\%), indicating violent suicides decreased among indoor workers. Considering suicides by violent methods show remarkable peaks in spring [2,43,47], it is plausible to expect seasonal spring peaks with people who are more likely to spend time in outdoor settings [82]. Migrant workers can be exposed to higher mental distress and suicide risk as dramatically depicted in the series of attempted or committed suicides in Foxconn production facilities in China between Jan and May 2010 [83-85]. However, seasonal variation of suicide in migrant populations needs to be further studied.

These findings seem to indicate that people who are more exposed to the outdoor environment have a greater seasonal spring peak in suicide - thus, suggesting that factors driving seasonality may be more abundant in the outdoor environment. For example, increased seasonal work related-stress in farmers and increased exposure to outdoor physico-chemico-biological factors such as day length, light, temperature, pollution, pathogens or allergens may contribute to more ample seasonal suicide peaks.

\section{Suicide Methods}

Suicide methods can be classified as either violent (i.e., hanging, firearms, drowning, jumping, cutting, or self-immolation) or non-violent (i.e., ingestion of poisons, drugs, gases, or vapors) in terms of lethality based on the International Classification of Diseases [80]. There appears to be seasonal variation of suicide completion by suicide methods. A number of researchers have reported seasonal variation of suicide by violent methods including hanging, jumping from a height, drowning, poisoning, and firearms $[3,41,47,66,86,87]$. Suicide rates by violent methods peak in spring/early summer and dip in winter, which is consistent with the general pattern of suicide seasonality. Hakko et al. [39] reported that suicide rates by violent methods increased by $16 \%$ in May, while it correspondingly decreased by $15 \%$ in December. The patterns of seasonal fluctuation in violent suicides are well 
replicated, regardless of geographical region. Studies conducted in Europe including Finland [39,88], Italy [47,68], Greece [48], Belgium [2,89], Greenland [37,90], Switzerland [1,81], UK [91], Australia, New Zealand [92], Asia [43], and the U.S. [93,94] found seasonal spring peaks in violent suicide rates. In Taiwan, however, the violent suicide peaks in summer rather than in spring [43].

Gender differences have been reported with the use of violent suicide methods. Lester and Frank analyzed a U.S. population-based data and reported seasonal spring peaks of suicide by poison, hanging, or firearms, in addition to seasonal autumn peaks for hanging or firearms among male victims [94]. In contrast, in female victims, they observed seasonal variation of suicide completion with spring and fall peaks by poison or hanging and with summer/late fall peaks by firearms. Furthermore, the study conducted by Yip et al. in which they evaluated Australia-New Zealand population based data, revealed a significant seasonal variation of suicide by hanging in Australian and New Zealand in males only [92].

Regarding non-violent methods, Hakko et al. [39] found two peaks of suicide rates within the non-violent subgroup approximately a $9 \%$ increase in spring and an $8 \%$ increase in fall. However, the majority of studies did not observe any significant seasonal spring peaks in suicides by non-violent methods $[2,43,68,89]$. Pollen counts have been particularly related to nonviolent suicides in women [19].

As one of the possible mechanisms to explain the significant spring peaks of violent suicides, we can consider the role of neurotransmitters in violent behaviors. For example, serotonin concentration, is often associated with impulsive and aggressive behaviors [95] and tryptophan (the main precursor of serotonin) concentration in the brain shows a prominent seasonal rhythm with lower plasma levels measured in spring in comparison to other seasons [96]. Thus, researchers have postulated that low levels of serotonin in the brain could possibly have an influence on impulsive drives, violent behaviors, and potentially result in an individual committing suicide by violent methods [68,96]. A counter argument against the proposition of serotonin mediation of violent suicide could stem from the findings from an Australian study in which hours of bright sunlight exposure were directly correlated with serotonin turnover in the brain, measured invasively [97]. Brain serotonin turnover was seven times higher during the summer than during the winter, thus not entirely consistent with a hypothesis of a serotonergic mediation of suicide seasonality (i.e., low serotonin in spring).

A number of researchers have argued that seasonal variation of suicide by specific methods was determined by the opportunities to access the methods [3]. Ajdacic-Gross et al. [3] reported that whereas firearms and knives are normally available during the whole year, poisoning (especially pesticides) occurred in the planting season and drowning and jumping are mostly used in outdoor activity season. Lahti et al. [66] found that suicide by shooting among Finnish adolescents occurred more frequently from August to October and its monthly pattern was positively related to the duration of daily sunshine hours, which were suggested to be related to increased firearm availability during the hunting season in addition to other psychosocial factors.

Seasonality of suicide by methods can vary across different time frames. Ajdacic-Gross et al. [81] looked at 120 year trends of suicide seasonality in Switzerland and determined that there was a decline of overall seasonal variation during 1969-2000 compared to 1881-1920. The most significant difference between the two periods was the attenuation of suicides by hanging and drowning, both of which previously had strong seasonal effects on suicide. Although statistically significant seasonal 
peaks in spring were exhibited in both periods, the strength of the association has been on the decline with regards to hanging.

\section{Conclusions}

Seasonal variation of suicide rates with the most common peak occurring in late spring or summer are one of the most consistent themes from environment-suicide research. In contrast, interactions between demographic factors, environmental factors and suicide methods have yielded inconsistent results. We synthesized Figure 2 to integrate variables related with seasonality of suicide.

Figure 2. A Model depicting the interplay of factors potentially involved in the Seasonality of Suicide. 5-HT $=5$-hydroxytryptamine; $\mathrm{DA}=$ dopamine; $\mathrm{NE}=$ norepinephrine.

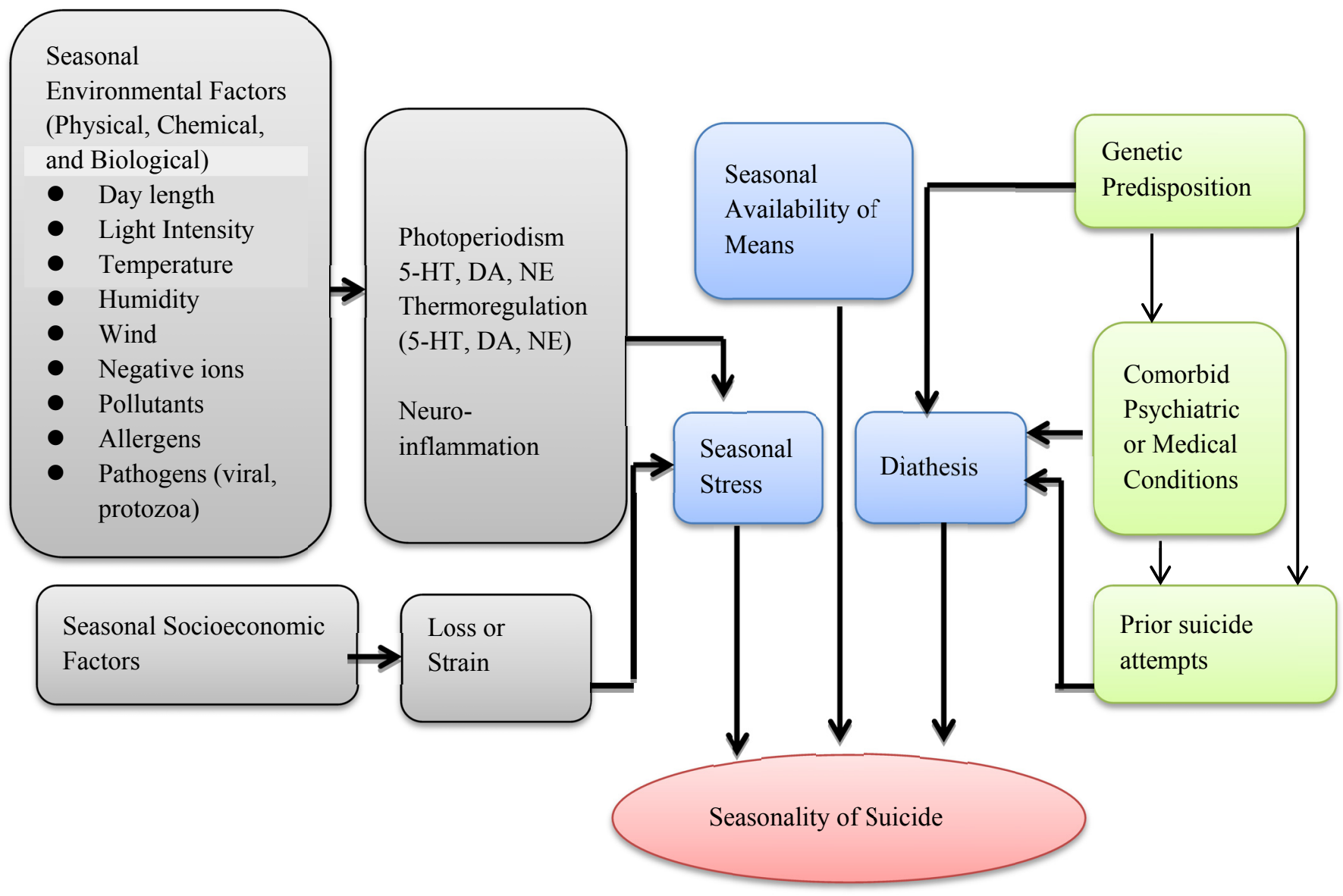

Although the seasonal patterns of suicidal behavior are highly replicated, the underlying mechanisms are poorly understood and efforts to isolate seasonal variables, such as bioclimatic and socioeconomic variables, to assist in identifying factors mediating seasonality have often resulted in inconclusive findings.

One of the explanations for this inconsistency could be differences in methodology across studies [29]. Obviously, all seasonality-suicide studies are inherently based on correlational studies which cannot explain causal relationships It is desirable to collect data spanning several years and including people from multiple geographical regions to avoid confounding effects from non- 
seasonality variables and over-generalization bias [26]. Unfortunately, many studies assessed seasonality over a relatively short period of time with data gathered in only one country or even smaller geographic unit [29]. Also, it will be important to establish a consistent set of multilevel variables all studies must account for when analyzing seasonal effects. For instance, in our recent study, after adjusting for the density of psychiatrists, urban vs. rural location and income, significant relationships between airborne allergens and suicide across space have been lost, suggesting a spurious relationship [98].

In some countries, seasonal suicide peaks have a tendency of being flattened in terms of reduced amplitude and smaller proportion of variance accounted for by the season. Recent studies using data from England and Wales [99], Hong Kong [100], Sweden [101], and Denmark [102] have demonstrated a diminishing seasonality tendency on suicides. However, this phenomenon does not apply in some other countries, such as Finland [20,39,41] and the United States [103], where a resilient seasonality pattern continues to be found for suicides or parasuicides. Overall, there might be a possibility that the contribution of season, while present, is so small that it can be irrelevant when other risk factors, such as gender and mental illnesses, are adjusted for. Few studies have examined seasonality in the context of other risk factors [104-106].

A better understanding of the mechanisms leading to seasonal peaks of suicide attempts and completions, may lead to identifying factors that could be amenable to preventative interventions and result, in the longer run, in flattening seasonal peaks of suicide and possibly, improved suicide prevention in general

\section{Acknowledgments}

Teodor T. Postolache was supported by R01MH074891 from NIH and, the American Foundation for Suicide Prevention. Jong-Min Woo was supported by the "Forest Science \& Technology Projects (S111111L020100)" from Republic of Korea Forest Service (PI, Woo) and by the National Evidencebased Healthcare Collaborating Agency (NM 11-003). Olaoluwa Okusaga was supported by the Psychiatry Residency Training Program/St.Elizabeth Hospital, Washington DC. We also thank Uttam Raheja for his help with Figure 2. The authors thank Christine Ballwanz for her indispensable assistance.

\section{Conflict of Interest}

The authors report no competing interests.

\section{References and Notes}

1. Ajdacic-Gross, V.; Wang, J.; Bopp, M.; Eich, D.; Rössler, W.; Gutzwiller, F. Are seasonalities in suicide dependent on suicide methods? A reappraisal. Soc. Sci. Med. 2003, 57, 1173-1181.

2. Maes, M. Seasonality in violent suicide but not in nonviolent suicide or homicide. Am. J. Psychiatry 1993, 150, 1380-1385. 
3. Ajdacic-Gross, V.; Bopp, M.; Ring, M.; Gutzwiller, F.; Rossler, W. Seasonality in suicideA review and search of new concepts for explaining the heterogeneous phenomena. Soc. Sci. Med. 2010, 71, 657-666.

4. Chew, K.S.Y.; McCleary, R. The spring peak in suicides: A cross-national analysis. Soc. Sci. Med. 1995, 40, 223-230.

5. Qin, P. Suicide risk in relation to level of urbanicity-A population-based linkage study. Int. J. Epidemiol. 2005, 34, 846-852.

6. Kung, H.C.; Pearson, J.L.; Liu, X. Risk factors for male and female suicide decedents ages 15-64 in the United States. Soc. Psych. Psych. Epidemiol. 2003, 38, 419.

7. Rock, D.; Greenberg, D.; Hallmayer, J. Season-of-birth as a risk factor for the seasonality of suicidal behaviour. Eur. Arch. Psychiatry Clin. Neurosci. 2006, 256, 98-105.

8. Lorant, V. A European comparative study of marital status and socio-economic inequalities in suicide. Soc. Sci. Med. 2005, 60, 2431-2441.

9. Smith, J.C.; Mercy, J.A.; Conn, J.M. Marital status and the risk of suicide. Am. J. Public Health 1988, 78, 78-80.

10. Preti, A. The influence of seasonal change on suicidal behaviour in Italy. J. Affect. Disord. 1997, 44, 123-130.

11. Souêtre, E. Seasonality of suicides: Environmental, sociological and biological covariations. J. Affect. Disord. 1987, 13, 215-225.

12. Qin, P.; Agerbo, E.; Mortensen, P.B. Suicide risk in relation to socioeconomic, demographic, psychiatric, and familial factors: A National register-based study of all suicides in Denmark, 1981-1997. Am. J. Psychiatry 2003, 160, 765-772.

13. Qin, P.; Mortensen, P.B.; Waltoft, B.L.; Postolache, T.T. Allergy is associated with suicide completion with a possible mediating role of mood disorder-A population-based study. Allergy 2011, 66, 658-664.

14. Töro, K. Relationship between suicidal cases and meteorological conditions. J. Forensic Leg. Med. 2009, 16, 277-279.

15. Kim, Y.; Kim, H.; Kim, D.-S. Association between daily environmental temperature and suicide mortality in Korea (2001-2005). Psychiatry Res. 2011, 186, 390-396.

16. Kim, C.; Jung, S.H.; Kang, D.R.; Kim, H.C.; Moon, K.T.; Hur, N.W.; Shin, D.C.; Suh, I. Ambient particulate matter as a risk factor for suicide. Am. J. Psychiatry 2010, 167, 1100-1107.

17. Okusaga, O.; Yolken, R.H.; Langenberg, P.; Lapidus, M.; Arling, T.A.; Dickerson, F.B.; Scrandis, D.A.; Severance, E.; Cabassa, J.A.; Balis, T.; Postolache, T.T. Association of seropositivity for influenza and coronaviruses with history of mood disorders and suicide attempts. J. Affect. Disord. 2011, 130, 220-225.

18. Lee, H.-C.; Lin, H.-C.; Tsai, S.-Y.; Li, C.-Y.; Chen, C.-C.; Huang, C.-C. Suicide rates and the association with climate: A population-based study. J. Affect. Disord. 2006, 92, 221-226.

19. Postolache, T.T.; Stiller, J.W.; Herrell, R.; Goldstein, M.A.; Shreeram, S.S.; Zebrak, R.; Thrower, C.M.; Volkov, J.; No, M.J.; Volkov, I.; Rohan, K.J.; Redditt, J.; Parmar, M.; Mohyuddin, F.; Olsen, C.; Moca, M.; Tonelli, L.H.; Merikangas, K.; Komarow, H.D. Tree pollen peaks are associated with increased nonviolent suicide in women. Mol. Psychiatry 2004, 10, 232-235. 
20. Partonen, T.; Haukka, J.; Viilo, K.; Hakko, H.; Pirkola, S.; Isometsä, E.; Lönnqvist, J.; Särkioja, T.; Väisänen, E.; Räsänen, P. Cyclic time patterns of death from suicide in northern Finland. J. Affect. Disord. 2004, 78, 11-19.

21. Vyssoki, B.; Praschak-Rieder, N.; Sonneck, G.; Blüml, V.; Willeit, M.; Kasper, S.; Kapusta, N.D. Effects of sunshine on suicide rates. Comp. Psychiatry 2012, in press.

22. Souetre, E. Influence of environmental factors on suicidal behavior. Psychiatry Res. 1990, 32, 253-263.

23. Altamura, C. Seasonal and circadian rhythms in suicide in Cagliari, Italy. J. Affect. Disord. 1999, 53, 77-85.

24. Rock, D. Increasing seasonality of suicide in Australia 1970-1999. Psychiatry Res. 2003, 120, 43-51.

25. Volpe, F.M.; Tavares, A.; Del Porto, J.A. Seasonality of three dimensions of mania: Psychosis, aggression and suicidality. J. Affect. Disord. 2008, 108, 95-100.

26. Deisenhammer, E.A.; Kemmler, G.; Parson, P. Association of meteorological factors with suicide. Acta Psychiatr. Scand. 2003, 108, 455-459.

27. Lambert, G.; Reid, C.; Kaye, D.; Jennings, G.; Esler, M. Increased suicide rate in the middleaged and its association with hours of sunlight. Am. J. Psychiatry 2003, 160, 793-795.

28. Ajdacic-Gross, V.; Lauber, C.; Sansossio, R.; Bopp, M.; Eich, D.; Gostynski, M.; Gutzwiller, F.; Rössler, W. Seasonal associations between weather conditions and suicide-Evidence against a classic hypothesis. Am. J. Epidemiol. 2007, 165, 561-569.

29. Dixon, P.G. Effects of temperature variation on suicide in five U.S. counties, 1991-2001. Int. J. Biometeorol. 2007, 51, 395-403.

30. Nejar, K.A.; Benseñor, I.M.; Lotufo, P.A. Sunshine and suicide at the tropic of Capricorn, São Paulo, Brazil, 1996-2004. Rev. Saude Publica 2007, 41, 1062-1064.

31. Maes, M. Synchronized annual rhythms in violent suicide rate, ambient temperature and the light-dark span. Acta Psychiatr. Scand. 1994, 90, 391-396.

32. Petridou, E.; Papadopoulos, F.; Frangakis, C.; Skalkidou, A.; Trichopoulos, D. A role of sunshine in the triggering of suicide. Epidemiology 2002, 13, 106-109.

33. Meares, R. A sex difference in the seasonal variation of suicide rate: A single cycle for men, two cycles for women. Br. J. Psychiatry 1981, 138, 321-325.

34. Micciolo, R. Seasonal variation in suicide: Is there a sex difference? Psychol. Med. 1989, 19, 199-203.

35. Koskinen, O.; Pukkila, K.; Hakko, H.; Tiihonen, J.; Väisänen, E.; Särkioja, T.; Räsänen, P. Is occupation relevant in suicide? J. Affect. Disord. 2002, 70, 197-203.

36. Hiltunen, L.; Suominen, K.; Lonnqvist, J.; Partonen, T. Relationship between daylength and suicide in Finland. J. Circadian Rhythms 2011, 9, 10:1-10:12.

37. Bjorksten, K.; Kripke, D.; Bjerregaard, P. Accentuation of suicides but not homicides with rising latitudes of Greenland in the sunny months. BMC Psychiatry 2009, 9, doi:10.1186/1471-244X-9-20.

38. Ruuhela, R.; Hiltunen, L.; Venalainen, A.; Pirinen, P.; Partonen, T. Climate impact on suicide rates in Finland from 1971 to 2003. Int. J. Biometeorol. 2009, 53, 167-175.

39. Hakko, H. Seasonal variation in suicide occurrence in Finland. Acta Psychiatr. Scand. 1998, 98, 92-97. 
40. Näyhä, S. Autumn incidence of suicides re-examined: Data from Finland by sex, age and occupation. Br. J. Psychiatry 1982, 141, 512-517.

41. Räsänen, P.; Hakko, H.; Jokelainen, J.; Tiihonen, J. Seasonal variation in specific methods of suicide: A national register study of 20234 Finnish people. J. Affect. Disord. 2002, 71, 51-59.

42. Papadopoulos, F.C.; Frangakis, C.E.; Skalkidou, A.; Petridou, E.; Stevens, R.G.; Trichopoulos, D. Exploring lag and duration effect of sunshine in triggering suicide. J. Affect. Disord. 2005, 88, 287-297.

43. Lin, H.C.; Chen, C.S.; Xirasagar, S.; Lee, H.C. Seasonality and climatic associations with violent and nonviolent suicide: A population-based study. Neuropsychobiology 2008, 57, 32-37.

44. Flisher, A.J.; Parry, C.D.H.; Bradshaw, D.; Juritz, J.M. Seasonal variation of suicide in South Africa. Psychiatry Res. 1997, 66, 13-22.

45. Rocchi, M.B.L.; Sisti, D.; Miotto, P.; Preti, A. Seasonality of suicide: Relationship with the reason for suicide. Neuropsychobiology 2007, 56, 86-92.

46. Oravecz, R.; Rocchi, M.B.L.; Sisti, D.; Zorko, M.; Marusic, A.; Preti, A. Changes in the seasonality of suicides over time in Slovenia, 1971 to 2002. J. Affect. Disord. 2006, 95, 135-140.

47. Preti, A.; Miotto, P. Seasonality in suicides: The influence of suicide method, gender and age on suicide distribution in Italy. Psychiatry Res. 1998, 81, 219-231.

48. Christodoulou, C.; Papadopoulos, I.N.; Douzenis, A.; Kanakaris, N.; Leukidis, C.; Gournellis, R.; Vlachos, K.; Papadopoulos, F.C.; Lykouras, L. Seasonality of violent suicides in the Athens greater area. Suicide Life Threat. Behav. 2009, 39, 321-331.

49. Nakaji, S.; Parodi, S.; Fontana, V.; Umeda, T.; Suzuki, K.; Sakamoto, J.; Fukuda, S.; Wada, S.; Sugawara, K. Seasonal changes in mortality rates from main causes of death in Japan. Eur. J. Epidemiol. 2004, 19, 905-913.

50. Ho, T.P.; Chao, A.; Yip, P. Seasonal variation in suicides re-examined: No sex difference in Hong Kong and Taiwan. Acta Psychiatr. Scand. 1997, 95, 26-31.

51. Tonelli, L.H.; Katz, M.; Kovacsics, C.E.; Gould, T.D.; Joppy, B.; Hoshino, A.; Hoffman, G.; Komarow, H.; Postolache, T.T. Allergic rhinitis induces anxiety-like behavior and altered social interaction in rodents. Brain Behav. Immun. 2009, 23, 784-793.

52. Tonelli, L.H.; Hoshino, A.; Katz, M.; Postolache, T.T. Acute stress promotes aggressive-like behavior in rats made allergic to tree pollen. Int. J. Child. Health Hum. Dev. 2008, 1, 305-312.

53. Tonelli, L.H.; Stiller, J.; Rujescu, D.; Giegling, I.; Schneider, B.; Maurer, K.; Schnabel, A.; Möller, H.J.; Chen, H.H.; Postolache, T.T. Elevated cytokine expression in the orbitofrontal cortex of victims of suicide. Acta Psychiatr. Scand. 2008, 117, 198-206.

54. Manalai, P.; Hamilton, R.G.; Langenberg, P.; Kosisky, S.E.; Lapidus, M.; Sleemi, A.; Scrandis, D.; Cabassa, J.A.; Rogers, C.A.; Regenold, W.T.; Dickerson, F.; Vittone, B.J.; Guzman, A.; Balis, T.; Postolache, T.T. Pollen-specific Immunoglobulin E positivity is associated with worsening of depression scores in bipolar patients during high pollen season. Bipolar Disord. 2012, in press.

55. Keiser, O.; Spoerri, A.; Brinkhof, M.W.; Hasse, B.; Gayet-Ageron, A.; Tissot, F.; Christen, A.; Battegay, M.; Schmid, P.; Bernasconi, E.; Egger, M. Suicide in HIV-infected individuals and the general population in Switzerland, 1988-2008. Am. J. Psychiatry 2010, 167, 143-150.

56. Strahilevitz, M.; Strahilevitz, A.; Miller, J.E. Air pollutants and the admission rate of psychiatric patients. Am. J. Psychiatry 1979, 136, 205-207. 
57. Szyszkowicz, M. Air pollution and emergency department visits for depression in Edmonton, Canada. Int. J. Occup. Med. Environ. Health 2007, 20, 241-245.

58. Henriksson, M.M. Mental disorders and comorbidity in suicide. Am. J. Psychiatr. 1993, 150, 935-940.

59. Valtonen, H.; Suominen, K.; Partonen, T.; Ostamo, A.; Lonnqvist, J. Time patterns of attempted suicide. J. Affect. Disord. 2006, 90, 201-207.

60. Haukka, J.; Suominen, K.; Partonen, T.; Lonnqvist, J. Determinants and outcomes of serious attempted suicide: A nationwide study in Finland, 1996-2003. Am. J. Epidemiol. 2008, 167, 1155-1163.

61. Reutfors, J.; Ösby, U.; Ekbom, A.; Nordström, P.; Jokinen, J.; Papadopoulos, F.C. Seasonality of suicide in Sweden: Relationship with psychiatric disorder. J. Affect. Disord. 2009, 119, 59-65.

62. Brådvik, L.; Berglund, M. Seasonal distribution of suicide in alcoholism. Acta Psychiatr. Scand. 2002, 106, 299-302.

63. Postolache, T.T.; Mortensen, P.B.; Tonelli, L.H.; Jiao, X.; Frangakis, C.; Soriano, J.J.; Qin, P. Seasonal spring peaks of suicide in victims with and without prior history of hospitalization for mood disorders. J. Affect. Disord. 2010, 121, 88-93.

64. Kim, C.D.; Lesage, A.D.; Seguin, M.; Chawky, N.; Vanier, C.; Lipp, O.; Turecki, G. Seasonal differences in psychopathology of male suicide completers. Comp. Psychiatry 2004, 45, 333-339.

65. Timonen, M.; Viilo, K.; Hakko, H.; Särkioja, T.; Meyer-Rochow, V.B.; Väisänen, E.; Räsänen, P. Is seasonality of suicides stronger in victims with hospital-treated atopic disorders? Psychiatry Res. 2004, 126, 167-175.

66. Lahti, A.; Räsänen, P.; Karvonen, K.; Särkioja, T.; Meyer-Rochow, V.B.; Hakko, H. Autumn peak in shooting suicides of children and adolescents from Northern Finland. Neuropsychobiology 2006, 54, 140-146.

67. McCleary, R.; Chew, K.S.; Hellsten, J.J.; Flynn-Bransford, M. Age- and sex-specific cycles in United States suicides, 1973 to 1985. Am. J. Public Health 1991, 81, 1494-1497.

68. Preti, A.; Miotto, P.; Coppi, M.D. Season and suicide: Recent findings from Italy. Crisis 2000, 21, 59-70.

69. Meares, R.; Mendelsohn, F.A.; Milgrom-Friedman, J. A sex difference in the seasonal variation of suicide rate: a single cycle for men, two cycles for women. Br. J. Psychiatry 1981, 138, 321-325.

70. Sebestyen, B.; Rihmer, Z.; Balint, L.; Szokontor, N.; Gonda, X.; Gyarmati, B.; Bodecs, T.; Sandor, J. Gender differences in antidepressant use-related seasonality change in suicide mortality in Hungary, 1998-2006. World J. Biol. Psychiatry 2010, 11, 579-585.

71. Mergl, R.; Havers, I.; Althaus, D.; Rihmer, Z.; Schmidtke, A.; Lehfeld, H.; Niklewski, G.; Hegerl, U. Seasonality of suicide attempts: Association with gender. Eur. Arch. Psychiatry Clin. Neurosci. 2010, 260, 393-400.

72. Barker, A.; Hawton, K.; Fagg, J.; Jennison, C. Seasonal and weather factors in parasuicide. Br. J. Psychiatry 1994, 165, 375-380.

73. Masterton, G. Monthly and seasonal variation in parasuicide. A sex difference. Br. J. Psychiatry 1991, 158, 155-157. 
74. Jessen, G.; Andersen, K.; Arensman, E.; Bille-Brahe, U.; Crepet, P.; De Leo, D.; Hawton, K.; Haring, C.; Hjelmeland, H.; Michel, K.; Ostamo, A.; Salander-Renberg, E.; Schmidtke, A.; Temesvary, B.; Wasserman, D. Temporal fluctuations and seasonality in attempted suicide in Europe. Arch. Suicide Res. 1999, 5, 57-69.

75. Kessler, R.C.; Berglund, P.; Borges, G.; Nock, M.; Wang, P.S. Trends in suicide ideation, plans, gestures, and attempts in the United States, 1990-1992 to 2001-2003. JAMA 2005, 293, 2487-2495.

76. Dome, P.; Kapitany, B.; Ignits, G.; Rihmer, Z. Season of birth is significantly associated with the risk of completed suicide. Biol. Psychiatry 2010, 68, 148-155.

77. Chotai, J.; Forsgren, T.; Nilsson, L.-G.; Adolfsson, R. Season of birth variations in the temperament and character inventory of personality in a general population. Neuropsychobiology 2001, 44, 19-26.

78. Chotai, J.; Salander Renberg, E. Season of birth variations in suicide methods in relation to any history of psychiatric contacts support an independent suicidality trait. J. Affect. Disord. 2002, 69, 69-81.

79. Micciolo, R.; Williams, P.; Zimmermann-Tansella, C.; Tansella, M. Geographical and urbanrural variation in the seasonality of suicide: Some further evidence. J. Affect. Disord. 1991, 21, $39-43$.

80. Christodoulou, C.; Douzenis, A.; Papadopoulos, F.; Papadopoulou, A.; Bouras, G.; Gournellis, R.; Lykouras, L. Suicide and seasonality. Acta Psychiatr. Scand. 2012, 125, 127-146.

81. Ajdacic-Gross, V.; Bopp, M.; Sansossio, R.; Lauber, C.; Gostynski, M.; Eich, D.; Gutzwiller, F.; Rössler, W. Diversity and change in suicide seasonality over 125 years. J. Epidemiol. Community Health 2005, 59, 967-972.

82. Kposowa, A.J.; McElvain, J.P.; Breault, K.D. Immigration and suicide: The role of marital status, duration of residence, and social integration. Arch. Suicide Res. 2008, 12, 82-92.

83. Cheng, Q.; Chen, F.; Yip, P.S. The Foxconn suicides and their media prominence: Is the Werther Effect applicable in China? BMC Public Health 2011, 11, doi:10.1186/1471-2458-11-7-841.

84. Li, X.; Stanton, B.; Fang, X.; Xiong, Q.; Yu, S.; Lin, D.; Hong, Y.; Zhang, L.; Chen, X.; Wang, B. Mental health symptoms among rural-to-urban migrants in China: A comparison with their urban and rural counterparts. World Health Popul. 2009, 11, 24-38.

85. Lin, D.; Li, X.; Wang, B.; Hong, Y.; Fang, X.; Qin, X.; Stanton, B. Discrimination, perceived social inequity, and mental health among rural-to-urban migrants in China. Community Ment. Health J. 2011, 47, 171-180.

86. Lester, D. Seasonal variation in suicide and the methods used. Percept. Mot. Skills 1999, 89, 160-165.

87. Kalediene, R.; Starkuviene, S.; Petrauskiene, J. Seasonal patterns of suicides over the period of socio-economic transition in Lithuania. BMC Public Health 2006, 6, doi:10.1186/1471-2458-6-40.

88. Hakko, H.; Räsänen, P.; Tiihonen, J. Secular trends in the rates and seasonality of violent and nonviolent suicide occurrences in Finland during 1980-95. J. Affect. Disord. 1998, 50, 49-54.

89. Linkowski, P.; Martin, F.; De Maertelaer, V. Effect of some climatic factors on violent and nonviolent suicides in Belgium. J. Affect. Disord. 1992, 25, 161-166. 
90. Björkstén, K.S.; Bjerregaard, P.; Kripke, D.F. Suicides in the midnight sun-A study of seasonality in suicides in West Greenland. Psychiatry Res. 2005, 133, 205-213.

91. Salib, E. Elderly suicide and weather conditions: Is there a link? Int. J. Geriatr. Psychiatry 1997, 12, 937-941.

92. Yip, P.S.; Chao, A.; Ho, T.P. A re-examination of seasonal variation in suicides in Australia and New Zealand. J. Affect. Disord. 1998, 47, 141-150.

93. Lester, D.; Frank, M.L. Seasonal variation in suicide rates in the United States. J. Clin. Psychiatry 1988, 49, PMID:3417626.

94. Lester, D.; Frank, M. Sex differences in the seasonal distribution of suicides. Br. J. Psychiatry 1988, 153, 115-117.

95. Coccaro, E.F. Central serotonin and impulsive aggression. Br. J. Psychiatry 1989, 8, 52-62.

96. Maes, M.; Scharpe, S.; Verkerk, R.; D'Hondt, P.; Peeters, D.; Cosyns, P.; Thompson, P.; Meyer, F.D.; Wauters, A.; Neels, H. Seasonal variation in plasma L-Tryptophan availability in healthy volunteers: Relationships to violent suicide occurrence. Arch. Gen. Psychiatry 1995, 52, 937-946.

97. Lambert, G.W.; Reid, C.; Kaye, D.M.; Jennings, G.L.; Esler, M.D. Effect of sunlight and season on serotonin turnover in the brain. Lancet 2002, 360, 1840-1842.

98. Woo, J.M.; Gibbons, R.D.; Rogers, C.A.; Qin, P.; Kim, J.B.; Roberts, D.W.; Noh, E.S.; Mann, J.J.; Postolache, T.T. Pollen counts and suicide rates. Association not replicated. Acta Psychiatr. Scand. 2012, 125, 168-175.

99. Yip, P.; Chao, A.; Chiu, C. Seasonal variation in suicides: Diminished or vanished. Br. J. Psychiatry 2000, 177, 366-369.

100. Yip, P.S.F.; Yang, K.C.T. A comparison of seasonal variation between suicide deaths and attempts in Hong Kong SAR. J. Affect. Disord. 2004, 81, 251-257.

101. Rihmer, Z.; Rutz, W.; Pihlgren, H.; Pestality, P. Decreasing tendency of seasonality in suicide may indicate lowering rate of depressive suicides in the population. Psychiatry Res. 1998, 81, 233-240.

102. Yip, P.S.F.; Yang, K.C.T.; Qin, P. Seasonality of suicides with and without psychiatric illness in Denmark. J. Affect. Disord. 2006, 96, 117-121.

103. Bridges, F.S.; Yip, P.S.F.; Yang, K.C.T. Seasonal changes in suicide in the united states, 1971 to 2000. Percept. Mot. Skills 2005, 100, 920-924.

104. Casey, P.; Gemmell, I.; Hiroeh, U.; Fulwood, C. Seasonal and socio-demographic predictors of suicide in Ireland: A 22 year study. J. Affect. Disord. 2011.

105. Corcoran, P.; Reilly, M.; Salim, A.; Brennan, A.; Keeley, H.S.; Perry, I.J. Temporal variation in Irish suicide rates. Suicide Life Threat. Behav. 2004, 34, 429-438.

106. Schreiber, G.; Dycian, A.; Kaplan, Z.; Bleich, A. A unique monthly distribution of suicide and parasuicide through firearms among Israeli soldiers. Acta Psychiatr. Scand. 1993, 87, 110-113.

(C) 2012 by the authors; licensee MDPI, Basel, Switzerland. This article is an open access article distributed under the terms and conditions of the Creative Commons Attribution license (http://creativecommons.org/licenses/by/3.0/). 